\title{
O corset como objeto- fetiche na Inglaterra Vitoriana e as crises de valores nas dinâmicas entre classe e gênero
}

Roseana Sathler Portes Pereira

Mestranda, Universidade de São Paulo / rosesathler@gmail.com Orcid: 0000-0002-3390-1855 / lattes 


\title{
O corset como objeto-fetiche na Inglaterra Vitoriana e as crises de valores nas dinâmicas entre classe e gênero
}

\begin{abstract}
RESUMO
Este artigo busca explorar as relações entre o corset e o fetichismo no século XIX e começo do século XX. Apoiado pela perspectiva de Anne McClintock, em Couro imperial Raça, gênero e sexualidade no embate colonial (2010), sobre o fetiche e as dinâmicas entre classe e gênero, o protagonismo do corset na manutenção da ociosidade doméstica feminina vitoriana é analisado. A investigação sugere que a crise de valor produzida pelo conflito entre os espaços públicos e privados, pela relação entre a agência masculina e a estagnação feminina, bem como a impossibilidade do gozo do ócio feminino, são encarnadas no corset - que se converte em objeto-fetiche. A recuperação dos escritos de Freud, o estudo das genealogias do fetiche e a retomada de sua origem etimológica ampliam as perspectivas de significação para a relação do corset com o corpo feminino oitocentista, cuja silhueta, desenhada pela corseteria, demarcava calculadamente as possibilidades de seu papel social.
\end{abstract}

Palavras-chave: corset. Fetichismo. Período vitoriano. 


\title{
The corset as a fetish object of Victorian England and the crisis of values into the dynamics between class and gender
}

\begin{abstract}
This article aims to explore the connections between the corset and fetishism in the nineteenth century and the beginning of the twentieth century. Supported by the perspective of Anne McClintock on Imperial Leather: Race, Gender and Sexuality in the Colonial Contest (2010), in regards to fetish and the class and gender dynamics, this articled analyzed the prominence of the corset in the maintenance of Victorian female domestic idleness. The scrutiny suggests the crisis of value conducted by the conflict among public and private spaces, by the connection among male agency, female stagnation and the impossibility of pleasure from female idleness are all embodied in the corset, which converts it into an object of fetishism. The recovery of the writings of Freud, the study of the genealogies of fetishism and the resumption of its etymological origin broadens the meaning of perspectives for the relation between the corset and the nineteenth centuryfemale body, whose silhouette, drawn by corsetry, delimited measuredly its possibilities in its social role.
\end{abstract}

Keywords: corset. Fetishism. Victorian era. 


\title{
El corsé como objeto fetiche en la Inglaterra victoriana y la crisis de valores en la dinámica entre clase y género
}

\begin{abstract}
RESUMEN
Este artículo busca explorar la relación entre el corsé y el fetichismo en el siglo XIX y principios del XX. Con el apoyo de la perspectiva de Anne McClintock, en Imperial Leather Race, género y sexualidad en la lucha colonial (2010), sobre el fetiche y la dinámica entre clase y género, se analiza el papel del corsé en el mantenimiento de la ociosidad doméstica victoriana. La investigación sugiere que la crisis de valor producida por el conflicto entre los espacios públicos y privados, la relación entre la agencia masculina y el estancamiento femenino, así como la imposibilidad de disfrutar del ocio femenino, se encarnan en el corsé, que se convierte en un objeto fetiche. La recuperación de los escritos de Freud, el estudio de las genealogías del fetiche y la reanudación de su origen etimológico amplían las perspectivas de significado para la relación entre el corsé y el cuerpo femenino del siglo XIX, cuya silueta, diseñada por la corsetería, calculó las posibilidades de su papel social.
\end{abstract}

Palabras clave: corsé. Fetichimo. Inglaterra victoriana. 


\section{INTRODUÇÃO}

O corset pode ser definido como uma vestimenta usualmente estruturada por camadas de tecido e hastes, ajustada ao corpo por meio de amarrações. Seu design adquiriu diferentes configurações ao longo de sua existência - com origem imprecisa. Ao restringir gestualidades e constringir volumes, o corset atuou como ferramenta para artificialismos, cujos significados podem ser identificados a partir de uma análise das dinâmicas socioculturais e econômicas (dinâmicas estas que ditaram o ritmo e conduziram a pluralidade das configurações da corseteria ao longo de sua trajetória).

No século XIX, o corset era usado por mulheres em diversos contextos sociais: o acesso à peça foi facilitado pelos processos industriais e pelas publicações segmentadas que indicavam precisamente seus processos de fabricação domésticos. Inovações tecnológicas foram implementadas em sua confecção e tais esforços tornaram o corset vitoriano único pela sua capacidade até então inédita de constrição.

Tal contexto permitiu que mulheres das classes trabalhadora, burguesa e aristocrática tivessem completo acesso à corseteria, possibilitando uma definição precisa para a silhueta feminina do século XIX. No cenário do apogeu de sua utilização, o final do século foi palco de intensas discussões acerca do uso do corset e, dentre os argumentadores, estavam médicos e reformadores do vestuário - que se constituíam por feministas e artistas, membros da sociedade e autoridades. O corset passa a ser alvo de críticas implacáveis, geralmente associadas à saúde pública e à maternidade.

Paralelamente, o uso do corset é incorporado a uma intensa produção de literatura fetichista, publicada em 
veículos como a The Englishwoman's Domestic Magazine. A autora Anne McClintock, em Couro imperial - Raça, gênero e sexualidade no embate colonial (2010) explora a genealogia do fetiche e as dinâmicas que constituem o seu processo formativo por meio do estudo da relação entre império e colônia na conjuntura da Inglaterra vitoriana. Tal mecanismo foi, neste artigo, utilizado como método para a investigação dos locais antagônicos que o corset ocupou em sua trajetória oitocentista.

Cabe reforçar o recorte temporal no qual o artigo se desenvolve. A despeito dos sólidos pontos de contato apontados entre a utilização do corset no século XIX e seu percurso posterior até a contemporaneidade, tal análise exige uma abordagem mais abrangente e multifacetada, tema que esse artigo não se propõe a abarcar.

\section{GENEALOGIAS DO FETICHE}

No cenário da Inglaterra vitoriana, Anne McClintock se pauta nas relações entre Império e Colônia para discutir conceitos que caracterizam o fetichismo. Couro Imperial sugere uma genealogia mais ampla para o fetiche, abarcando dinâmicas entre raça, classe e gênero para além dos domínios das perversões eróticas de Freud. Segundo McClintock, o "discurso ocidental sobre o fetichismo já tinha pelo menos quatro séculos antes que 0 falo fosse identificado como seu princípio organizador central" (2010, p. 277). A etimologia de "fetiche" remete ao termo português "feitiço", associado à arte mágica ou à feitiçaria. A palavra foi incorporada pela igreja católica medieval em seus éditos disciplinares da sexualidade descontrolada feminina e, séculos mais tarde, por Sigmund Freud (2007), insolitamente, em sua teoria da falta feminina. Entrementes, 
fetiche também foi o termo empregado pelos exploradores portugueses "para descrever os misteriosos amuletos e objetos rituais preferidos pelos povos africanos" da costa ocidental do continente (MCCLINTOCK, 2010, p. 278).

Definido pela autora como "deslocamentos para um objeto (ou pessoa) de contradições que o indivíduo não pode resolver no nível pessoal" (2010, p. 276), o fetiche foi determinante na emergência de uma economia capitalista mercantil, na qual o choque entre a sociedade feudal cristã e a sociedade africana fundada em linhagens provocou uma inédita crise de valor. Os impactos desse violento encontro foram sentidos, sobretudo, nas necessárias trocas comerciais, como estabelecer "relações econômicas e culturais recíprocas com povos cujos sistemas de valor eram radicalmente diferentes" (2010, p. 279). Assim

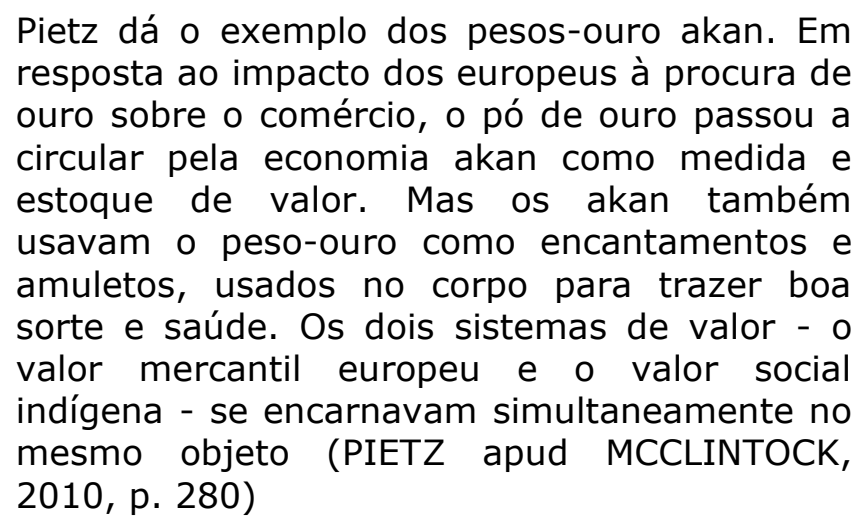

A negociação do ouro só foi possível a partir da equiparação de valores atribuídos ao mineral. Ainda que heterogêneos, os valores relegados ao mesmo objeto representavam, cada qual, a sua sociedade. A relação comercial torna-se, portanto, dependente da resolução de tais conflitos de valor.

Em seu ensaio Le Fetichisme dans L'Amour, de 1887, o pedagogo e psicólogo francês Alfred Binet deslocou o termo fetiche para o campo das perversões sexuais - com 0 
objetivo de categorizar o fascínio libidinal sobre membros do corpo ou objetos inanimados. Para ele, a paixão dedicada a tais objetos era da mesma ordem das associações de valor a objetos considerados mágicos pelas "primitivas" tribos africanas colonizadas.

Freud publica em 1927 seu consagrado estudo Fetichismo. A partir de casos clínicos, localiza a origem do fetichismo na tentativa de preservação na crença do pênis materno: "o fetiche é um substituto do pênis da mulher (da mãe) em que o menininho outrora acreditou e que - por razões que nos são familiares - não deseja abandonar" (FREUD, 2007, p. 95). Ao constatar a ausência do pênis da mãe, o menino sente, no mesmo golpe, a ameaça de sua própria castração. Em consequência de uma aversão aos órgãos genitais femininos reais, um objeto, portanto, é eleito como substituto do pênis materno: "Mas esse interesse sofre também um aumento extraordinário, pois o horror da castração ergueu um monumento a si próprio na criação desse substituto" (2007, p. 95). Tais objetos podem sugerir uma semelhança visual com o pênis ou, ainda, se relacionar com algum objeto ou partes de corpo que estejam associadas à última impressão (no percurso visual do menino) anterior ao trauma.

Assim, o pé ou o sapato devem sua preferência como fetiche - ou parte dela - à circunstância de o menino inquisitivo espiar os órgãos genitais da mulher a partir de baixo, das pernas para cima; peles e veludo - como por longo tempo se suspeitou - constituem uma fixação da visão dos pêlos púbicos, que deveria ter sido seguida pela ansiada visão do membro feminino; peças de roupa interior, que tão freqüentemente são escolhidas como fetiche, cristalizam o momento de se despir, o último momento em que a mulher ainda podia ser encarada como fálica (FREUD, 2007, p. 96) 
$\mathrm{Na}$ transferência do pênis da mãe para um objeto, a crença de que, de fato, a mulher teve um falo é mantida e abandonada. O substituto do pênis representa um compromisso com esse suposto: "No entanto, por meio do fetiche, é possível produzir um objeto que, ao mesmo tempo, é uma aparência posta como aparência e que permite ao sujeito "agir como se não soubesse" estar diante de uma aparência" (SAFATLE, 2006, p. 48). Na argumentação freudiana, a menina não tem lugar na cena da castração que origina o fetiche.

Em seu artigo Fetichismo e subjetividade feminina, Denise Teles Freire Campos (2010) se apoia nos textos dos pesquisadores Roudinesco e Plon para destacar que o fetichismo feminino não se desenvolve pela projeção do pênis da mãe em um objeto-fetiche, mas sim pela relação com um objeto libidinal (componente fetichista) que se tornará o prolongamento do corpo da mãe:

O mesmo "componente fetichista" deve ser interrogado no caso das mulheres que se prestam ao prazer dos fetichistas, pois, como assinala Clavreul (1990), pouco importa se esta parceira finja gostar ou apenas se submeta às práticas do perverso, o que está em jogo é o fascínio que este último exerce, de tal modo que a parceira sofra igualmente da lei do fetiche, que substitui a lei da diferença entre os sexos (a ausência de pênis na mãe) como causa do desejo (CAMPOS, 2010, p. 22)

McClintock salienta que Schor atribui o fascínio do fetichismo à indecidibilidade entre "o reconhecimento da castração e sua negação" (MCCLINTOCK, 2010, p. 302), mas reforça que é exatamente o compromisso com a indecibilidade que produz o fascínio pelo objeto-fetiche. Enfatiza a necessidade de se "abrir a genealogia do fetichismo a explicações historicamente mais frutíferas e teoricamente mais sutis" (2010, p. 304), uma vez que não 
sendo "um substituto universalmente fálico, o fetiche pode ser qualquer objeto sob o sol" (2010, p. 276). O resgate genealógico do termo propõe uma ampliação do objetofetiche para além do falocentrismo: "Em todo fetiche há a insistência no caráter factício do objeto (que não é estranho à origem portuguesa da palavra: 'feitiço, factício, fetiche')" (SAFATLE, 2006, p. 50).

A partir de uma perspectiva mais ampla, McClintock identifica traços recorrentes, ainda que não universais, para desenhar um padrão correspondente à emergência do fetiche e o seu ciclo estrutural, que se apresenta como

uma contradição social experimentada num
nível intensamente pessoal; o deslocamento da
contradição para um objeto ou pessoa, que se
torna a encarnação da crise de valor; o
investimento de intensa paixão (erótica ou
não) no objeto-fetiche; e a recorrência
repetitiva e muitas vezes ritual do objeto-
fetiche na cena da memória pessoal ou da
memória histórica (MCCLINTOCK, 2010, p.
276)

O ciclo estrutural de McClintock sobre o fetichismo pode orientar uma análise fetichista sobre a utilização do corset no século XIX e seu posterior e discutível declínio. Ademais, sua compreensão do fetiche para além do domínio sexual freudiano possibilita um panorama reflexivo mais abrangente.

\section{O CORSET}

Corsets (ou espartilhos) consistem em peças de vestuário cujo uso é destinado à parte superior do corpo. Tradicionalmente confeccionados em tecido, podendo conter uma ou várias camadas, comumente possuem estruturação feita a partir de barbatanas (hastes internas) e são 
ajustados por meio de amarração nas costas a fim de proporcionar alteração na silhueta natural do corpo humano.

O costume de atar a região abdominal é identificado em diversas culturas. Artefatos que promoviam efeitos muito similares aos do corset podem ser observados na Deusa das Serpentes cretense (2000-1500 a.C.) com sua "cintura esguia envolta por um cinto torcido" (KÖHLER, 1993, p. 103). Em uma análise dos afrescos minoicos é possível constatar que também seus idólatras ostentavam cinturas artificialmente esguias: tanto homens quanto mulheres apresentam a região demarcada por um largo cinturão indicando particularmente uma rigorosa exigência de construção corporal (DOYLE, 1997, p. 01).

No começo do século XVI, as vestimentas na Inglaterra e na França passaram a ser compostas por dois componentes principais: corpete e saia. Deixar o corpete independente da saia possibilitou um ajuste mais intenso e o desenvolvimento de trajes que se assemelhassem mais aos gibãos (tipo de colete rígido) masculinos já estruturados (WAUGH, 2004, p. 17).

Desde então, a modelagem e estrutura dos corsets se desenvolveram, assumindo diferentes configurações, em sintonia com o zeitgeist vigente. A funcionalidade de sua modelagem serviu a padrões de beleza e comportamento próprios de cada período.

A postura aristocrática do século XVII era orgulhosa $\mathrm{e}$ teatral, evocava a estética da verticalidade (STEELE, 2001, p. 13), cuja demanda objetivava produzir uma postura altiva. Para atender a essa imposição, o corset "consistia em um grande número de barbatanas colocadas bem juntas e revestidas com tecido de ambos os lados" (KÖHLER, 1993, p. 389), sua circunferência era cônica e sua extensão abrangia até a linha da cintura, onde possuía uma estrutura 
arranjada para proporcionar volume sob a saia inferior, de modo a oferecer um contraste imediato.

$\mathrm{Na}$ França do final do século XVIII, uma versão mais flexível do corset já estava incorporada na vestimenta da classe trabalhadora. No exame dos guarda-roupas realizado pelo historiador francês Daniel Roche sobre os inventários parisienses, cerca de $63 \%$ das criadas, artesãs, lojistas e esposas de funcionários públicos utilizavam corset, assim como também 50\% das mulheres assalariadas. Na nobreza, $81 \%$ das mulheres também adotavam o espartilho (ROCHE, 2007, p. 175).

No século XIX, o uso do corset se popularizou por todas as classes sociais. O costume de atar meninas em bodices (espartilhos leves e levemente estruturados), iniciado ainda no século XVIII, se populariza e é alvo de um extenso debate nos campos da medicina e da moral.

É na era vitoriana que os corsets adquirem a sua configuração mais popular, e que permanece como referência no imaginário contemporâneo: a sua modelagem mais alongada e abrangente pressiona e evidencia a linha da cintura e, na maioria dos exemplares, se prolonga até a bacia.

Inovações tecnológicas fundamentais produziram novas possibilidades: a popularização dos ilhóses metálicos, criados em 1823 (SUMMERS, 2001, p. 13), permitiu intensificar a pressão do ajuste sem o rompimento dos orifícios por onde a amarração passa. A ampla utilização do busk em duas peças (artefato que viabiliza o fechamento frontal enquanto proporciona suporte para a região abdominal) data de 1829 (WAUGH, 2004, p. 79) e sua introdução propiciou uma inédita praticidade no vestir.

Um corset vitoriano promovia, portanto, considerável restrição física. As barbatanas dispostas em seus painéis 
notadamente curvos podiam agora, como nunca antes, pressionar o busto, tórax, bacia e principalmente a cintura, conformando-os a uma outra configuração. Esta servia sob medida à imagem de uma mulher sonolenta, indisposta, atormentada por desfalecimentos e histeria, "definhando de tédio; incapaz de constância, decisão ou estatura, a mulher de classe média era, até recentemente, consistentemente menosprezada" (MCCLINTOCK, 2010, p. 241).

O preço de um corset podia variar entre $\$ 1.00$ e $\$ 6.00$. A confecção em larga escala possibilita uma massiva adesão à peça. Exemplares produzidos em tamanho padronizado passam a ser comercializados a preços acessíveis para a classe trabalhadora, e corsetières especializadas atendem à clientela que procura materiais mais sofisticados e peças sob medida.

A historiadora Leigh Summers destaca que a corseteria era essencial tanto para construir a feminilidade quanto para construir uma identidade de classe: "A corseteria era apreciada por mulheres de classe média conscientes da moda porque ela proporcionava à carne os contornos adequados à classe" (SUMMERS, 2001, p. 10)1.

Em sua maioria, as mulheres da classe trabalhadora usavam corsets com a mesma frequência do que as mulheres de classe média (SUMMERS, 2001, p. 11). Não obstante a facilidade a seu acesso, ocasionada pela industrialização, muitas dessas mulheres também estavam aptas para confeccionar seus próprios corsets. Na França, as mulheres de classe operária, casadas, exerciam funções em sua própria casa, desempenhando tarefas relacionadas aos têxteis: "confeccionavam lingerie, espartilhos, luvas, casacos e coletes masculinos, ou fiavam" (CRANE, 2006, p. 106), além de comporem a classe trabalhadora das próprias indústrias de confecção de espartilhos. Publicações femininas 
como a The Young English Woman, The Workwoman's Guide e a Harpers Bazaar editavam rotineiramente textos ilustrados com detalhes a fim de ensinar sua confecção doméstica (SUMMERS, 2001, p. 11).

\section{O CORSET E O TRABALHO FEMININO}

Fazer uso do mesmo estilo de vestuário das classes média e alta cobrava o seu preço, uma vez que o vestuário da época era rico em volumes e ornamentos, restritivo e apropriado ao ócio da mulher decorativa aristocrática (CRANE, 2006, p. 70). Ao fim do século XVIII, à mulher das classes média e alta já não cabia mais nenhuma função institucional; pelo contrário, a sua condição social era a de ornamentação doméstica, "vivia apenas para adornar a ambição mundana do marido" (MCCLINTOCK, 2010, p. 240). A adesão das mulheres da classe operária ao estilo da aristocracia demandava, portanto, um grande esforço. Diane Crane aponta que a adesão à moda vigente

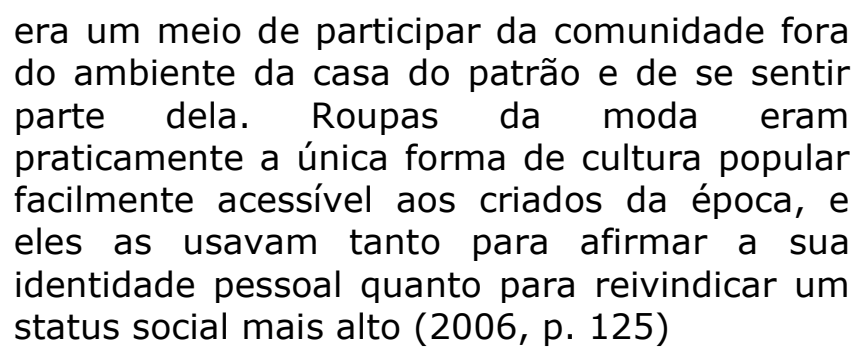

O vestuário restritivo de mulheres de classes média e alta era reproduzido também por jovens que trabalhavam em fábricas, ainda que a exposição das amplas crinolinas ao maquinário industrial representasse uma verdadeira ameaça à sua integridade física ao desempenhar suas atividades (CRANE, 2006, p. 126). Sua utilização era um atravanco não 
apenas para a classe trabalhadora, mas também para a classe média.

A imagem de gozo do ócio e permanente lazer da mulher de classe média, bem como seu portentoso vestuário e a abundância de móveis e aparatos decorativos que compunham o ambiente doméstico, era imprescindível ao status familiar ostentado pelo homem, mas a realidade da economia doméstica não correspondia às condições exigidas para oportunizar a mimese aristocrática. Para viabilizar a estrutura familiar adequada à distinção da classe média e à inércia feminina seria necessário o emprego de, pelo menos, três criados domésticos. Porém apenas uma pequena parcela da classe alta e média alta poderia arcar com tal remuneração. A maior parte dos lares ingleses contava com apenas uma criada responsável por toda a diversidade dos afazeres domésticos;

com exceção da ínfima elite verdadeiramente apta ao lazer - o ócio era menos um regime de inércia imposto às mofinas esposas filhas da classe média do que um laborioso e demorado papel característico desempenhado por mulheres que queriam pertencer à classe "respeitável". Para a maioria das mulheres cujos maridos ou pais não podiam pagar criadagem suficiente para o ócio genuíno, o trabalho doméstico tinha de ser acompanhado pelo esforço sem precedente histórico de tornar invisível cada sinal desse trabalho (MCCLINTOCK, 2010, p. 243).

A partir de 1857 o vestuário feminino típico aristocrático, copiado pelas demais classes, compreendia o uso de crinolinas: "o termo designava, inicialmente, uma armação feita com crina de cavalo" (KÖHLER, 1993, p. 527). Tratavase de uma ampla armação complexa, formada por hastes verticais e horizontais e, em alguns casos, revestida por painéis almofadados. Seu formato e dimensões se alteraram incontáveis vezes no decorrer deste século, atingindo 
grandes proporções - a ponto de demandar o emprego de mais de dez metros de tecido na confecção das saias que as revestiam (KÖHLER, 1993, p. 527). Desse modo,

qualquer atividade realizada com as crinolinas levava as mulheres à fadiga. Somados ao uso do espartilho, era muito comum elas terem desmaios, falta de ar, inapetência, ficavam sempre pálidas e com aspecto doentio (XIMENES, 2010, p. 62).

A palidez natural era valorizada e realçada por meio da maquiagem, que tornava olheiras e veias azuladas (XIMENES, 2010, p. 62). Para o apagamento dos sinais de desgaste, ocasionados pelo trabalho doméstico, o hábito de esfregar as mãos com toucinho à noite e dormir com luvas era rotineiro (MCCLINTOCK, 2010, p. 245). Todos os sinais que evidenciavam a agência das mulheres, sobretudo no trabalho relacionado com a limpeza da casa, cozinha e cuidado com os filhos, eram criteriosamente ocultados através de uma aparência que evocava a fragilidade.

\section{A CRISE DE VALOR DA CORSETERIA}

Principalmente a partir da segunda metade do século, o uso do corset passa a ser alvo de debates no campo da medicina, dos interessados na reforma do vestuário e feministas da primeira onda. A escritora feminista Elizabeth Stuart Phelps protesta em 1873

Fora com os espartilhos! .... Não, não os dê a empregada. Nunca prenda em outra mulher, pelo sagrado nome da caridade, as correntes das quais você mesma escapou. Nunca dê seus brincos, quando tiver adquirido desgosto pelo seu uso. Nunca faça presentes das bugigangas e de ridicularias que seu gosto amadurecendo descarta. O que é intrinsecamente impróprio ou injusto é tão impróprio e injusto para a sua 
cozinheira quanto para si.... Então, queime os corsets! Não, não salve nem as barbatanas. Você nunca mais precisará de ossos de baleia. Faça uma fogueira do aço cruel que reinou sobre o conteúdo do seu abdômen e do seu tórax por tantos anos imprudentemente e dê um suspiro de alívio; pois a sua "emancipação", asseguro-lhe, a partir deste momento começou (PHELPS apud STEELE, 2001 , p. 60$)^{2}$

As opiniões sobre o uso do corset por mulheres e meninas desencadearam múltiplas reações. Tal movimentação fomentou inicialmente uma busca pela reforma do corset e não pela sua abolição, visto que se acreditava que o corpo da mulher era mais fraco do que o dos homens, e por isso necessitava de suporte (STEELE, 2001, p. 52).

O mesmo se pensava acerca das crianças: atá-las em versões de corsets mais maleáveis e menos estruturadas era garantia de que se desenvolveriam com uma postura adequada. Mesmo os meninos, ainda no século XVIII, também eram atados até certa idade (SUMMERS, 2001, p. 63).

A redução da cintura era vista como um instinto natural (STEELE, 2001, p. 54) e o formato decorrente de sua utilização era essencial para a adesão ao vestuário da moda, que não poderia ser usado sem a redução da cintura. É importante ressaltar que o corset também servia como sutiã: além de oferecer sustentação para o busto, alguns modelos possuíam enchimento na região a fim de proporcionar volume e um formato arredondado para as mamas (STEELE, 2001, p. 54). Debates a respeito da elaboração de corsets, cuja estrutura e modelagem fossem saudáveis, ocorreram com muita frequência no final do século XIX e começo do século XX. Havia uma proliferação 
de estudos e patentes que pretendiam a elaboração de corsets capazes de oferecer a preservação da saúde.

Porém, um significativo movimento anticorset começa a ganhar corpo por meio da literatura médica, baseada em sua interferência nas leis de reprodução e por meio de manifestações feministas que apoiavam uma reforma do vestuário em prol de uma maior vitalidade que proporcionaria paridade com os homens (STEELE, 2001, p. 59). Reformadores do vestuário, como a feminista norte americana Amelia Bloomer, reivindicavam a utilização de uma vestimenta utilitária e não decorativa. O empreendimento de se criar uma nova forma para o vestuário envolveu também a classe artística:

\footnotetext{
Mas já em 1900, parece que o desenhador belga Henry Van der Velde exibira 'roupas reformadas' em Kerfeld (sic), centro da indústria têxtil da Alemanha e seus desenhos, que troçavam dos espartilhos, apresentavam cinturas subidas e eram construídos sobre ' princípios arquitectónicos' (...) (WILSON, 1985, p. 288)
}

O pintor Gustave Klimt, em parceria com Emilie Flöge sua amiga e proprietária de uma boutique vienense - , motivado pelo anti-industrialismo da Wiener Werkstätte, também criou vestidos e outros trajes com características amplas e arejadas. Klimt já era adepto do uso de túnicas, vestia-se com elas para gozar de conforto e liberdade de movimentos: "um misto de caftã oriental e traje nô, do teatro tradicional japonês, foi concebida por ele mesmo e simbolizava o retorno a uma vida simples e natural" (BRANDSTÄTTER, 2000, p. 9).

O movimento de emancipação feminina e a reforma do vestuário, somado às admoestações dos artigos médicos e o desenvolvimento da silhueta da moda levaram progressivamente a uma reconfiguração do corset, que 
passou a ter uma frente plana e curvas a partir das laterais em direção às costas (peças características do período eduardiano), passando pelo achatamento completo da bacia e quadris (sem enfatizar propriamente a cintura) entre 1910 e 1920.

O sucesso das criações do couturier Paul Poiret, que promovia uma nova figura por meio de silhueta alongada em vestidos fluidos e confortáveis, foi o elemento definidor de uma nova estética, que se tornou diretriz para inúmeros designers (LAVER, 2005, p. 224). Para essa nova configuração da moda vigente o uso do corset tradicional não era mais necessário. Sua presença foi substituída por peças mais leves, em fibras elásticas e sintéticas, como o sutiã e as cintas, que assumiram uma infinidade de formatos (STEELE, 2001, p. 148). Esse período pode ser associado a uma profunda mudança do papel social da mulher, que durante e após a primeira guerra mundial passa a assumir novas funções que não lhe cabiam (STEELE, 2001, p. 151).

No mesmo período do desaparecimento da corseteria tradicional, as dietas e exercícios se tornaram populares: a revista Vogue em 1908 proclama a magreza das mulheres que seguem a moda "Quão magras, quão graciosas, quão elegantes são as mulheres!"3 (STEELE, 2001, p. 146). A historiadora de moda Valerie Steele defende que o corset, sua estrutura e seu formato foram internalizados: "o espartilho nunca desapareceu realmente; foi antes convertido em outros tipos de roupas de baixo e finalmente no corpo moderno bem-exercitado" (SVENDSEN, 2010, p. 93). Concomitante ao ocaso do corset, as dietas, exercícios e posteriormente os procedimentos cirúrgicos passaram a ser incorporados de modo a se resgatar a figura acorsetada, que dita os padrões de beleza vigentes na cultura ocidental contemporânea (SVENDSEN, 2010, p. 92). 
Em 1947 o couturier Christian Dior resgata o corset com o lançamento do seu New Look. A cintura de vespa e saia ampla evidenciavam sua inspiração na moda do final do século XIX. Seu sucesso foi tamanho que seu shape foi responsável por definir a moda da década de 1950 (BRAGA, 2005, p. 95). Nos anos 1980, designers como Vivienne Westwood e Jean-Paul Gaultier resgatam o uso do corset, inserindo-o em suas coleções como peça externa, e não mais como lingerie (STEELE, 2001, p. 167). Desde então, o corset ressurge na moda, mas em uma posição bem diversa, ganha espaço em composições para passarela, para trajes de festa ou ainda é inserido na vestimenta de tribos urbanas como a gótica e a sadomasoquista, evocando um passado não muito distante.

\section{CORSET E FETICHISMO}

Partindo da genealogia aberta proposta por Anne McClintock, é possível relacionar o corset dentro da dinâmica fetichista do período vitoriano. Tendo como suporte a estrutura proposta pela autora, é possível pensar o fascínio exercido pelo corset no século XIX e sua estreita relação com as dinâmicas de poder nas quais as mulheres estavam inseridas (e as quais o corset não apenas servia, como também personificava e contribuía para a manutenção de uma figura frágil, resignada e presa fisicamente ao espaço doméstico).

McClintock estrutura o fetiche em traços recorrentemente identificáveis: um padrão que, para além do silogismo falocêntrico freudiano, pode se aplicar a qualquer objeto ou sujeito envolto em uma dinâmica de poder e fascinação, encantamento e magia, conforme a sua própria etimologia denuncia. 


\subsection{Fase 1: uma contradição social experimentada num nível intensamente pessoal}

A vestimenta vitoriana das classes altas, amplamente difundida e reproduzida por todas as demais classes, era composta em sua totalidade por características meramente ornamentais. Longe de se pautar nas necessidades anatômicas, a teatralidade dos trajes servia unicamente ao vestuário de uma mulher inerte, frágil e devotada à ociosidade. Para tanto,

as saias armadas pelas crinolinas eram verdadeiramente prodigiosas, ao ponto de tornar impossível que duas mulheres entrassem juntas em uma sala ou sentassem no mesmo sofá, pois os babados dos vestidos ocupavam todo o espaço (LAVER, 2005, p. 180).

O extenso volume de delicados tecidos, o comprimento das mangas, o número de babados, a incômoda e descomunal crinolina revestida com camadas acolchoadas, a simulação de olheiras e veias com maquilagem para realçar a palidez e por fim o corset tinham a função de corroborar essa imagem.

A figura da mulher inerte era central para a manutenção dos limites da domesticidade. O culto da domesticidade estava relacionado com a preservação da tradição que a sociedade, caracterizada pelo ritmo frenético de suas transformações, buscava salvaguardar. Ao homem ator, criador e descobridor da história era destinado o espaço público, enquanto o domínio privado dependia da preservação feminina, e resguardá-lo exigia imobilidade. Conforme comenta e cita McClintock sobre o historiador britânico Sir Charles Petrie, 
O fato de um homem manter suas mulheres no ócio tornou-se o sinal da sua importância ... O exemplo espalhou-se pela classe média até que o trabalho se tornasse uma infelicidade e uma desgraça para as mulheres. (PETRIE apud MCCLINTOCK, 2010, p. 241)

O argumento da continuidade da tradição pelas mulheres pode ser endossado por meio do papel da mãe e da avó na escolha do vestuário das mulheres da família. Por meio deste hábito familiar, podemos inferir que "O peso cultural atribuído à propriedade e à respeitabilidade dificultou que as mulheres abandonassem o espartilho, ainda que elas quisessem"4 (STEELE, 2001, p. 51).

Neste contexto, o trabalho doméstico realizado pelas mulheres da classe média, incapazes de reproduzir o ócio genuíno da classe superior, configurava uma imensa contradição social. O trabalho doméstico revelava a subalternidade de sua classe, assim como a inferioridade do ofício do homem, cuja remuneração era insuficiente para sua abolição. Entrementes, denunciava perigosamente a permanente dependência do trabalho não remunerado feminino para a manutenção da economia vitoriana.

\subsection{Fase 2: o deslocamento da contradição para um objeto ou pessoa, que se torna a encarnação da crise se valor}

A ativista política Frances E. Russel atribuía ao vestuário de sua época o refreamento das perspectivas das mulheres para o avanço social. "Moda ridícula constritiva"5 (RUSSEL apud SUMMERS, 2001, p. 98), proclama Russel, que acusava a moda de trazer problemas de saúde e ser prova da inferioridade feminina (SUMMERS, 2001, p. 98). 
As mulheres que transgrediam as fronteiras vitorianas entre o público e o privado, entre o trabalho e o lazer, entre o trabalho pago o não pago, tornavam-se cada vez mais estigmatizadas como espécimes de regressão racial. Tais mulheres, dizia-se, não habitavam propriamente a história, mas eram protótipos de humanos anacrônicos: infantis, irracionais, regressivas e atávicas, existindo num tempo permanentemente anterior dentro da modernidade (MCCLINTOCK, 2010, p. 75)

Valerie Steele destaca que o novelista inglês Charles Reade devotou grande parte de seu volume $A$ Simpleton, de 1873, para denegrir o uso dos corsets: "jogue essa máquina diabólica [corset] no fogo"6 (READE apud STEELE, 2001, p. 50). Por meio das vozes feministas da primeira onda, da medicina vitoriana e dos reformadores do vestuário, o corset encarnou a crise de valor entre progresso e tradição, e entre o privado e o doméstico: "De fato, o corset tem sido descrito como uma peça "essencialmente vitoriana", por causa de seu papel na criação e no policiamento da feminilidade da classe média"7 (STEELE, 2001, p. 35).

\subsection{Fase 3: o investimento de intensa paixão (erótica ou não) no objeto-fetiche}

Entre 1867 e 1874 a The Englishwoman's Domestic Magazine publicou mais de 150 cartas a respeito de corsets e do Tight Lacing. O intenso volume de correspondências obrigou a revista a criar um suplemento dedicado exclusivamente este nicho (STEELE, 2001, p. 93). Tight Lacing é o nome da prática de usar corsets enfaticamente ajustados na cintura a fim de proporcionar reduções corporais artificiais definitivas. Sua prática, no período vitoriano, é cercada por controvérsias. Alguns historiadores, como Leight Summers, defendem que a prática era regra 
entre as mulheres do século XIX, mas evidências dizem 0 contrário - a historiadora de moda Valerie Steele defende que o Tight Lacing era raramente praticado entre as mulheres vitorianas; porém, a prática era amplamente difundida entre a literatura fetichista. Um intenso erotismo cercava o assunto: a imagem de mulheres e jovens mártires do tight lacing exibindo cinturas minúsculas e também homens forçados a reduzirem a cintura por meio do uso do corset permeavam o imaginário vitoriano e as ilustrações da The Englishwoman's Domestic Magazine (EDM).

Mas Steele afirma que as "minúsculas cinturas mencionadas em fontes como a EDM não eram de forma alguma típicas das mulheres vitorianas" (STEELE, 1997, p. 67). A historiadora corrobora sua pesquisa por meio da análise das propagandas de corsets, nas quais a grade de tamanhos era divulgada (também o faz através da pesquisa museológica: para quem espera cinturas proporcionalmente minúsculas, a análise de tais peças é "desapontadora", cita Steele.

Para além da paixão erótica, Summers cita os historiadores de moda $\mathrm{C}$. Willet e Phyllis Cunnington para resgatar um costume curioso da classe média em voga no ano de 1890: entre as mulheres solteiras, acreditava-se que a circunferência da cintura deveria ser mantida com a medida correspondente à idade em que a jovem intencionava se casar, e por esse motivo esforçavam-se enormemente para conservar a medida de 21 polegadas no máximo (SUMMERS, 2001, p. 88).

\subsection{Fase 4: a recorrência repetitiva e muitas vezes ritual do objeto-fetiche na cena da memória pessoal ou da memória histórica}


A crise de valor da corseteria tradicional teve o seu apogeu no começo do século XX. Apesar dos inúmeros movimentos sociais que apregoavam a sua extinção, a efetiva derrocada da peça foi promovida pelo surgimento de uma nova silhueta na moda parisiense, proposta pelos emergentes criadores do período. Uma figura alongada, jovem e excessivamente esguia passa a ser desejada (STEELE, 2001, p. 153). A prática de exercícios e a adesão a dietas restritivas tornavam-se, portanto, habituais. É o que demonstra Sevendsen, para quem a dieta do final do período vitoriano "foi um fenômeno que se difundiu na classe média e que estava relacionada com a regulação do consumo de alimentos, de tal modo que disso resultasse um corpo idealizado, esbelto" (2010, p. 85).

Paralelamente aos novos hábitos, novas peças modeladoras são também introduzidas, com a finalidade de proporcionar redução dos volumes corporais. Contam com uma configuração diferenciada em comparação com a corseteria tradicional: são confeccionadas com fios elásticos e apresentam estrutura mais maleável. Permanecem como componente integral do guarda-roupas feminino até a década de 60 (STEELE, 2001, p. 143). Grande parcela da crítica médica sobre a utilização do corset partia da crença de que a peça seria responsável por incapacitar o corpo da mulher para a maternidade, provocar complicações no parto e má formação fetal. Curiosamente, após a extinção da corseteria tradicional foi possível notar uma considerável decadência nas taxas de natalidade (STEELE, 2001, p. 138). A responsabilidade de conservação das formas do corset por meio de dietas restritivas e exercícios físicos impactou profundamente os hábitos femininos.

O fetichista romancista francês Rétif de la Bretonne proclama: "O corpo feminino nu 'se torna arte através dos 
controles dos limites da forma'"8 (BRETONNE apud STEELE, 2001, p. 137). A recorrência do objeto-fetiche ressoou extraordinariamente na configuração dos corpos na virada do século. Estes, livres das amarras da corseteria tradicional, se mantiveram conformados, ora por vestimentas derivadas do espartilho, ora pela vigilância dos limites do corpo nu, cuja apreciação permanecia (e permanece) condicionada à semelhança das formas do corset.

\section{CONSIDERAÇÕES FINAIS}

A aplicação do padrão de McClintock, imbuído no funcionamento do fetichismo como diretriz para o estudo da trajetória do corset no período vitoriano, fundamenta hipóteses sobre o curioso percurso entre o seu apogeu e seu ocaso.

Entre os séculos XVI e XIX, de modo mais ou menos expressivo, o corset foi artigo indispensável na vestimenta feminina, com o intuito de conformar os corpos às configurações determinadas pelos padrões de comportamento e beleza, ideais de cada época. Na era vitoriana, portanto, sua modelagem e estrutura corroborava o arquétipo da mulher ociosa, fragilizada, débil e inerte cuja agência se restringia ao espaço doméstico à serviço do marido. É neste período que seu uso atinge máxima popularização e passa a compor o guarda-roupas de mulheres pertencentes à todas as classes sociais.

Ao examinar o interior das estruturas dos papéis oitocentistas de gênero e de classe, McClintock refuta a autenticidade do gozo do ócio feminino, revelando, portanto, uma série de inconsistências relacionadas ao apagamento do trabalho doméstico e à negação da importância da mulher 
para a manutenção da economia vitoriana. É exatamente em meio à efervescência das crises de valores vitorianas que a obsessão (erótica ou não) pelo corset é instaurada por meio de intensos debates acerca de sua utilização, e que resultam em sua demonização e consequente decadência. O protagonismo do corset nas contradições imbuídas nas dinâmicas entre gêneros e classes vitorianas acaba por lhe imputar o status de objeto-fetiche

A despeito deste decurso, evidências de sua permanência são encontradas na conformação dos torsos nos séculos $X X$ e XXI - definidos pelo corset imaginário que atua através da vigilância dos corpos, instrumentalizada por meio de dietas e exercícios físicos. Ainda que ausente, o corset segue definindo silhuetas, em concordância com os padrões estéticos e sociais.

\section{Notas}

1 "Corsetry was prized by fashion-conscious, middle-class women because it crafted the flesh into class-appropriate contours" (SUMMERS, 2001, p.10).

2 "Off with the corsets!...No, don't give them to Biddy. Never fasten about another woman, in the sacred name of charity, the chains from which you have yourself escaped. Never give away your earrings, when you have acquired a distaste for the wearing of them. Never make presents of the gew-gaws and frippery which your maturing taste discards. What is intrinsically unbecoming or unrighteous is as unbecoming and unrighteous for your cook as for yourself ... So burn up the corsets! No, nor do you save the whalebones. You will never need whalebones again. Make a bonfire of the cruel steel that has lorded it over the contents of the abdomen and thorax so many thoughtless years, and heave a sigh of relief; for your "emancipation", I assure you, 
has from this moment begun (PHELPS apud STEELE, 2001, p. 60)

3 "How slim, how graceful, how elegant women look!" (STEELE, 2001, p.146).

4 "The cultural weight placed on propriety and respectability made it difficult for women to abandon the corset, even they wanted to" (STEELE, 2001, p. 51).

5 "Ridiculous constrictive fashions" (RUSSEL apud SUMMERS, 2001, p. 98)

6 throw that diabolical machine [i.e. corset] into the fire" (READE apud STEELE, 2001, p. 50)

7 Indeed, the corset has been described as a "quintessentially Victorian" garment, because of its role in creating and policing middle-class femininity" (STEELE, 2001, p. 35).

8 "The nude female body 'become[s] art by controlling the limits of the form'" (BRETONNE apud STEELE, 2001, p. 137).

\section{REFERÊNCIAS}

BRAGA, João. Reflexões sobre moda - Volume 1. São Paulo: Anhembi Morumbi, 2005.

BRANDSTATTER, Christian. Klimt \& a Moda. São Paulo: Cosac \& Naify, 2000.

CAMPOS, Denise Teles Freire. A perversão feminina e o laço social na atualidade. Tempo psicanalítico. Vol.42, n.2, pp. 287-311. 2010.

http://pepsic.bvsalud.org/scielo.php?script=sci_arttext\&pid=S010 1-48382010000200003.

CRANE, Diana. A moda e seu papel social. Classe, gênero e identidade das roupas. São Paulo, Senac. 2006.

DOYLE, R. Waisted Efforts: An Illustrated Guide to Corset Making. Stratford. Sartorial Press Publications. 1997.

FREUD, Sigmund. (1927) Fetichismo. Escritos sobre a psicologia do inconsciente, volume III. [coord. geral da tradução Luiz Alberto Hanns]. Rio de Janeiro: Imago, 2007.

KÖHLER, Carl. História do vestuário. São Paulo: Martins Fontes, 1993. 
LAVER, James. A roupa e a moda: uma história concisa. São Paulo: Cia das Letras, 2005.

MCCLINTOCK, Anne. Couro imperial: raça, gênero e sexualidade no embate colonial. Campinas: Editora da Unicamp, 2010.

ROCHE, Daniel. A cultura das aparências: uma história da indumentária (séculos XVII-XVIII). São Paulo: SENAC, 2007

SAFATLE, Vladimir. Sexo, simulacro e políticas da paródia. Revista do Departamento de Psicologia, UFF. Vol. 18, n.1, pp. 39-56. 2006. Disponível

em:

http://www.scielo.br/pdf/rdpsi/v18n1/a04v18n1.pdf.

STEELE, Valerie. Fetiche: sexo, moda \& poder. Rio de Janeiro: Rocco, 1997.

STEELE, Valerie. The corset: a cultural history. New York: Yale University, 2001.

SUMMERS, Leigh. Bound to please: a history of the Victorian corset. Oxford: Berg Publishers, 2001.

SVENDSEN, Lars. Moda: Uma filosofia. Rio de Janeiro: Zahar, 2010.

WAUGH, Norah. Corsets and crinolines. New York: Theatre Arts Books, 2004.

WILSON, Elizabeth. Enfeitada de Sonhos: moda e modernidade. Rio de Janeiro: Edições 70, 1985.

XIMENES, Maria Alice. Moda e arte na reinvenção do corpo feminino do século XIX. São Paulo: Estação das Letras e Cores, 2010. 